\title{
Ethical Responsibilities in the Field of Periodontology and Periodontics: Implications in an Indian Scenario
}

\author{
Simran Parwani ${ }^{1 *}$ and Rajkumar Parwani ${ }^{2}$ \\ ${ }^{1}$ Professor and Head, Department of Periodontology, VYWS Dental College and \\ Hospital, Amravati, Maharashtra, India \\ ${ }^{2}$ Professor MDS, Department of Oral and Maxillo-facial Pathology, VYWS Dental \\ College and Hospital, Amravati, India \\ *Corresponding Author: Simran Parwani, Professor and Head, Department of \\ Periodontology, VYWS Dental College and Hospital, Amravati, Maharashtra, India.
}

Received: February 18, 2020

Published: March 06, 2020

(C) All rights are reserved by Simran

Parwani and Rajkumar Parwani.

\begin{abstract}
Clinical science that deals with the periodontium in health and disease is called Periodontology, the practice of which is known as Periodontics. Dental ethics govern every phase of treatment, including the diagnosis and treatment planning, patient education, quality of work performed, achieving satisfactory outcomes, determining fees, communication with referring dentists and accurate and honest record keeping. Dental Associations while serving as the national "watchdog" on ethics also contribute to protect the rights of organized dentistry through nationwide communication and by supporting local, state and federal legislation. Ethical responsibilities of a general dentist are that they should diagnose and treat periodontal disease properly. Proactive and conservative care along with long-term maintenance is critical. Patients with advanced disease who do not respond to initial treatment should be referred to the periodontist. A periodontist as a specialist should have a thorough knowledge of all non-surgical and surgical procedures (including periodontal plastic surgery and implants), maintenance care, oral physiotherapy, oral medicine (for diagnosing and treating systemic health as it relates to the periodontal disease), temporomandibular joint disorders and myofascial pain dysfunction syndrome. Obstacles in controlling and preventing periodontal disease in an Indian scenario are that it is a painless disease and low socio-economic strata of majority of the population. General dentists practicing Periodontics and Periodontists should take the onus to converge the knowledge of Periodontology and apply it ethically for the benefit of the community at large.
\end{abstract}

Keywords: Ethics; Periodontology; Periodontics; Periodontist; General Dentists; India

\section{Introduction}

Periodontal disease is a disease of the supporting structures of the teeth, involving the periodontal ligament, cementum, alveolar bone and the various tissue components of gingiva [1]. American Academy of Periodontology (AAP) has defined gingivitis as an inflammatory lesion confined to the tissues of the gingiva [2]. The progression of an established gingivitis to the advanced lesion heralds the onset of periodontitis - an inflammatory disease of the periodontal tissues. The features of periodontitis include loss of connective tissue attachment on the root surface and exposure of cementum: apical migration of the junctional epithelium, which can result in gingival recession or pocket formation; alveolar bone loss and an increase in tooth mobility [1].

Clinical science that deals with periodontium in health and disease is called Periodontology, the practice of which is Periodontics [3]. A periodontist is a dentist who specializes in the prevention, diagnosis and treatment of periodontal disease, and in the placement of dental implants [4].

Evolution of periodontics/periodontology

In the mid-nineteenth century, John W. Riggs [5] (1811 - 1885) was the leading authority on periodontal disease and its treatment 
in the U.S. to the point that all inflammatory lesions to which we now apply the names 'Gingivitis' and 'Periodontitis' were referred to as 'Riggs disease'. He was the first individual to limit his practice to Periodontics and therefore can be considered the first specialist in this field. In 1948, upon recommendation by the AAP, the American Dental Association (ADA) recognized the American Board of Periodontology as an official speciality board for Periodontists and Periodontics. This was the second such board to be recognized by the ADA, Oral surgery being the first [6].

\section{Training programs}

Various training programs in Periodontology are being conducted with slight variations all over the world. Before applying to a postgraduate training program, one must first complete a dental degree. In India, Periodontology is offered as a specialization field of dentistry. Periodontists attend a Master of Dental Surgery (MDS) program (of three years) affiliated with dental colleges in India. The minimum qualification required for this course is a Bachelor of Dental Surgery (BDS) degree [4]. After MDS, Ph.D. degree can also be availed.

\section{Contribution of the dentists to the society}

Periodontal diseases are preventable and controllable to a large degree, particularly in early stages. Since the dentist's professional obligation is to keep teeth healthy and to prevent their loss, knowledge of periodontal disease and its prevention and treatment are of paramount concern to the dentist. Without such knowledge, a dentist cannot be considered fully competent [7].

\section{Evidence-based practice}

There is significant variation in clinical decisions among dentists as a result of discrepancies in diagnosis, the need for and types of dental treatment recommended and the outcomes of these interventions [8]. Evidence-based practice has been defined as improving treatment outcomes by using research evidence, along with clinical experience and patient preferences, in making decisions about individual patients [9].

A successful practitioner is the one who can make decisions in the face of clinical uncertainty [10]. Ignoring research findings can present a significant barrier to the provision of optimal care. Clinicians should attempt to base decisions on current evidence to ensure more consistent and relevant treatment outcomes. Publication of research advances (from the results of Randomized Controlled Trials and Systematic Reviews) has allowed practitioners to incorporate the evidence into clinical practice [11].
Implementing evidence-based change means providing training to current dental students [11].

\section{Training BDS students}

In India, one of the most important aspects for achieving and sustaining good quality practice of Periodontics is imparting complete training to BDS students. BDS students who cannot obtain MDS degree practice all branches of dentistry. Therefore, during the course itself, they should obtain maximum knowledge so that they can deliver the best services to the community when they are practicing. First of all, students should be encouraged to remain punctual. BDS students should learn proper history-taking to explore different periodontal diseases with their characteristic signs and symptoms (as per classification of periodontal diseases contributed by AAP in 1999 [12] and World Workshop in 2017) [13] and their respective treatment modalities. Students should also be made to learn how to instruct patients about proper brushing techniques. Students should know when to prescribe interdental aids, mouthwashes and desensitizing agents. They should learn to encourage smokers/tobacco chewers to quit the habit because periodontitis is a multifactorial disease with multiple risk factors (systemic, environmental, behavioral and genetic) [14], tobacco smoking/chewing being the most prevalent in India. Here, a dentist can be of great motivational influence.

\section{Tobacco smoking}

It is a well-established risk-factor for periodontitis $[15,16]$. Effects of smoking on etiology and pathogenesis of periodontal disease are microbiological, immunological and physiological [17]. A direct relationship exists between smoking and the prevalence of periodontal disease [18]. Studies comparing the response to periodontal therapy in smokers, previous smokers and non-smokers have shown that smoking has a negative impact on the response to therapy. However, former smokers respond similarly to nonsmokers [19].

Another most important aspect that BDS students/dental practitioners should thoroughly learn is the necessity of supportive periodontal therapy and when should a general dentist refer a periodontal patient to a specialist. These are the ethical responsibilities of general practitioners in treatment of periodontal disease.

\section{Supportive periodontal therapy}

After phase I therapy is completed, patients should be placed on a schedule of periodic recall visits for maintenance care to prevent 
recurrence of the disease as patients who are not maintained in a supervised recall program subsequent to active treatment show obvious signs of recurrent periodontitis [20].

\section{Referral of patients to the periodontist}

A major issue faced by all dentists is when to refer a patient. It is unethical to treat a patient beyond the practitioner's expertise. It is a good rule of thumb not to treat a patient if all the possible complications cannot be managed. A growing conundrum since the $1980 \mathrm{~s}$ in periodontal treatment involves "practice management seminars which have been encouraging general practitioners to partake in soft tissue management protocols, and where nonsurgical treatment is looked upon as a much more important income center in the business model [21]. These "profit centers" should not supersede the patient's treatment needs. Clearly, the patient's best interest should determine treatment and referral patterns [22].

Where to draw the line between the cases to be treated in the general dental office and those to be referred to a specialist varies for different practitioners and patients. Patients who require localized gingivectomy/flap curettage usually can be treated by a general dentist (class $\mathrm{A} /$ mild or localized periodontitis patients). If periodontal destruction necessitates surgery on the distal surfaces of second molars, extensive osseous surgery or complex regenerative procedures, the patient is best treated by a specialist (class $\mathrm{C}$ / advanced periodontitis patients). A third group of patients, who do not accommodate into any of these groups are known as the "candidates for referral" (class B/moderate periodontitis patients) [23].

The $5 \mathrm{~mm}$ standard has been proposed as a guideline for referral (Figure 1) [24]. If the patient has clinical attachment loss (CAL) of $5 \mathrm{~mm}$ or greater at re-evaluation after phase I therapy, referral should be considered.

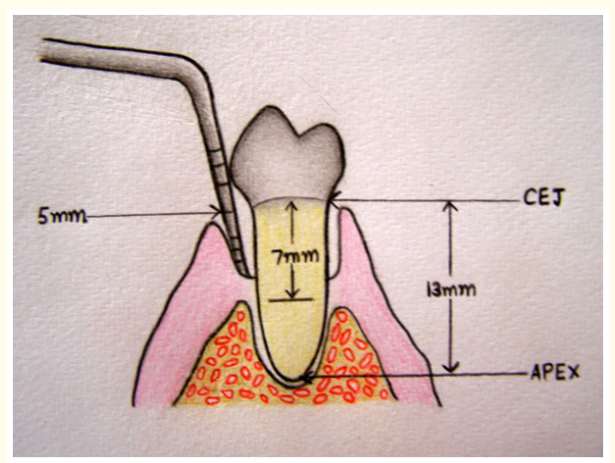

Figure 1: The $5 \mathrm{~mm}$ standard for referral to a periodontist is based on root length and clinical attachment loss.
Other factors for referral include: Extent of the disease (localized, deep pockets); root length (short); hyper-mobility of teeth; difficulty in scaling and root planing (deep pockets with exposed furcations); extensive sub-gingival restorative work; young patient (aggressive disease) and non-resolution of inflammatory lesions after scaling and root planing.

Maintenance phase of therapy should be performed according to Merin [25] classification designed for recall intervals of various classes of patients with periodontal disease. Supportive periodontal therapy of class A patients should be taken care of by a general dentist, that of class $C$ patients by a specialist and that of class $B$ patients by both alternatively (Figure 2) [25].

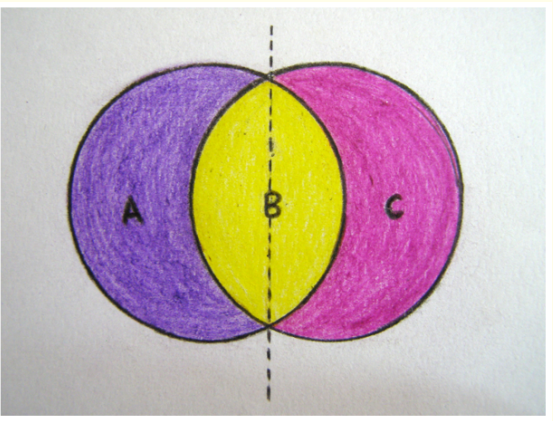

Figure 2: Scheme for determining which practitioner should perform periodontal maintenance in patients with different degrees of periodontitis.

\section{Continuing dental education (CDE) programs}

It is an ethical duty for all professionals to maintain, improve and update their knowledge and skills as per evidence-based knowledge. CDE has been an important and stimulating part of all dentist's clinical practice life. Because of its importance, CDE is now mandatory for maintaining licensure in many states. The type and amount of CDE varies from state to state and is determined by their respective boards. e.g. California requires 50 hours of study every 2 years. Half that amount must relate directly to clinical care; the other half can pertain to practical management issues, state law, federal regulations such as Occupational Safety and Health Administration (OSHA) and Health Insurance Portability and Accountability Act (HIPAA) guidelines and cardiopulmonary resuscitation (CPR) certification [22].

Senior practitioners should be encouraged to bring amendments in their practice without involvement of psychological issues 
in making clinical decisions, especially while facing clinical uncertainty. To facilitate this process, various organizations of Periodontology/Periodontics have been developed.

\section{Professional organizations}

General dentists and Periodontists should come together and share the knowledge of Periodontology/Periodontics with each other and discuss the various aspects of diagnosis, prognosis and treatment planning in accordance with the upcoming concepts of evidence-based dentistry. Clinicians who are practicing Periodontics can contribute practical lessons that they have learnt from their own practices. Academicians can share their experiences and knowledge that they have gained during teaching their students. All this can be acquired with the help of presentation of posters, paper presentations and publications in journals of the organizations of Periodontology (Indian Society of Periodontology, Asian Pacific Society of Periodontology, British Society of Periodontology, American Academy of Periodontology, etc.).

\section{Role of dental organizations}

Dental Associations while serving as the national "watchdog" on ethics also contribute to protect the right of organized dentistry through nationwide communication and by supporting local, state and federal legislation [22].

Ethics in dental practice

Ethical behavior is to serve the larger community and not serving only self [22]. It is important that a dental practitioner should have knowledge, skill and technical competence; however, the traits of compassion, kindness, integrity, fairness and charity will define a true professional [22]. Whether it is local or international, ethical behavior depends on honesty and on protecting rights of the patient. Organized dentistry mandates certain forms of ethical behaviors beyond the primary activity of patient care. Community service is expected. Research and development performed in an evidence-based manner, along with patents and copyrights that do not restrict patient treatment, are needed to continually advance the level of care. Furthermore, all individual organizations should also be self-governing to prevent discrimination, abuse, overtreatment or overbilling and false or misleading advertising [22].

\section{Practical considerations in ethical practice of dentistry}

The everyday practice of dentistry is typically filled with ethical decisions to be made by the dentist and dental hygienist. Ethics govern every phase of treatment, covering a wide range, like: Di- agnosis and treatment planning, patient education, quality of work performed, achieving satisfactory outcomes, determining fees, insurance company charges, communication with referring dentists and accurate and honest record keeping.

Dentists should integrate their personal and monetary needs with the need to serve their community with quality work. "Value gaps" should not arise, which states that "Patient's primary needs and wishes are that they be treated respectfully, ethically and professionally" [26]. Ethics of dentistry echo this goal, and dentists must not violate this principle by under-treating, over-treating or overcharging [22].

\section{Responsibility of a periodontist}

A periodontist as a specialist should have a thorough knowledge of all non-surgical as well as surgical procedures, maintenance care, and oral physiotherapy [22,27]. Another important area that falls under the large, important umbrella of oral medicine is diagnosing and treating systemic health as it relates to the periodontal process as well as diagnosing and treating oral pathology $[22,28]$. Furthermore, a thorough knowledge of temporomandibular joint disorder and myofascial pain dysfunction syndrome is also needed.

Periodontal plastic surgery is also an important component in the scope of Periodontics. These oral surgical cosmetic procedures depend on partnership with the restorative dentist to achieve excellent esthetic results [22].

At the same time, Periodontists should get postdoctoral periodontal training programs in intravenous and conscious sedation for patient comfort and safety [29]. All Periodontists should also remain abreast with the biology of soft and hard tissues and the necessary skills and training in the surgical techniques needed to place an implant. Furthermore, periodontists should have an excellent inter-relationship with prosthodontists who restore the implants and improve the quality of patient's life [30].

\section{Discussion}

Practitioners should not be negligent in the treatment of the patient [22]. They should follow the key issues set by the American Dental Association (ADA) Code of Professional Conduct i.e. Patient autonomy - patient knowledge and participation, non maleficence - do no harm to the patient, beneficence - do only good for the patient, justice - fairness, veracity - truthfulness [22]. 
Legal issues with ethical implications that dental organizations must untertake include: Aiding unlicensed practitioners, improper billing issues or insurance fraud, improper use of auxiliary staff, improper prescription of controlled substances, confidential intervention programs for dental practitioners who are addicted to drugs, control over improper advertising by dentists in order to compete for patients and investigation of other transgressions, such as sexual abuse as they relate to the dentist's license [22].

Very few epidemiological studies have been conducted in India on the prevalence of periodontitis where the authors have concluded that our country's population (particularly adults and economically weak subjects) is highly susceptible to periodontitis. But, there is a very urgent need for standardized population-based studies with a robust design to identify the true prevalence of periodontitis, which in turn will help in planning oral health policies and creating the necessary infrastructure [31].

Major obstacles in controlling and preventing periodontal disease in India are:

A. Majority of lesions are silent (less/no pain in destructive lesions).

B. A good percentage of population is below poverty line (low socio-economic status and residing in rural areas where a few number of dentists are available).

C. Sparse provision of medical insurance for dental treatment.

In addition to the role of professional dental organizations, we (general dentists and periodontists) as professionals should join our hands to converge the knowledge of Periodontology existing in diversifying directions. In this way, we can save the field of Periodontics and help it grow by application of its knowledge in our community. It has been truly stated, "Faith sees the invisible, believes the unbelievable and achieves the impossible".

\section{Conclusion}

Every general dentist (practicing Periodontics) and Periodontist should have a holistic approach towards each and every patient (with periodontal disease) of the community. In this way, we can practically apply the knowledge of Periodontology for the betterment of the patients.

\section{Bibliography}

1. Seymour RA., et al. "The pathogenesis of periodontal disease". In: Seymour RA, Heasman PA, Macgregor LM, editors. Drugs, diseases and the periodontium. Tokyo: Oxford University Press; (1992):1-10.

2. Aiguier JE., et al. "Report of the committee on nomenclature of the American Academy of Periodontology". Journal of Periodontology 8 (1937): 88-95.

3. Grant DA., et al. "Periodontal health and disease". In: Periodontics. 6th ed. St. Louis, Missouri: The CV Mosby Company (1988): 3-22.

4. American Academy of Periodontology. PERIO.ORG, What is a Periodontist.

5. Shklar G and Carranza FA. "The Historical Background of Periodontology”. In: Newman MG, Takei HH, Klokkevold PR, Carranza FA, editors. Carranza's Clinical Periodontology. 10th ed. St. Louis, Missouri: Saunders (2006): 1-10.

6. Gold SI. "Periodontics". The past Part (I). Early sources". Journal of Clinical Periodontology 12 (1985): 79-97.

7. Brady WF. "Periodontal disease awareness". Journal of the American Dental Association 109 (1984): 706-710.

8. Bader JD and Shugars DA. "Variation, treatment outcomes and practice guidelines in dental practice”. Journal of Dental Education 59 (1995): 61-95.

9. Sackett DA., et al. "Evidence-based medicine: how to practice and teach EBM". London: Churchill Livingstone (2000).

10. Hunink M and Glaziou P. "Managing Uncertainty". In: Hunink M, Glaziou P, editors. Decision making in health and medicine. New York: Cambridge University Press (2001): 36.

11. Abt E. "Implementing Evidence-Based Decisions in Clinical Practice". In: Newman MG, Takei HH, Klokkevold PR, Carranza FA, editors. Carranza's Clinical Periodontology. 10th ed. St. Louis, Missouri: Saunders (2006): 36-43.

12. Armitage GC. "Development of a classification system for periodontal diseases and conditions". Annals of Periodontology 4 (1999): 1-6.

13. Caton JG., et al. "A new classification scheme for periodontal and peri-implant diseases and conditions- Introduction and key changes from the 1999 classification". Journal of Clinical Periodontology 45 (2018): S1-S8. 
14. Novak MJ and Novak KF. "Chronic Periodontitis". In: Newman MG, Takei HH, Klokkevold PR, Carranza FA, editors. Carranza's Clinical Periodontology. 10th ed. St. Louis, Missouri: Saunders; 2006. p. 494-499.

15. American Academy of Periodontology. "Position paper: Epidemiology of periodontal diseases". Journal of Periodontology 67 (1996): 935-945.

16. Papapanou PN. "Risk assessments in the diagnosis and treatment of periodontal diseases". Jouranl Dental Educcation 62 (1998): 822-839.

17. Novak MJ and Novak KF. "Smoking and periodontal disease". In: Newman MG, Takei HH, Klokkevold PR, Carranza FA, editors. Carranza's Clinical Periodontology. 10th ed. St. Louis, Missouri: Saunders (2006): 251-258.

18. Ismail AI., et al. "Epidemiologic patterns of smoking and periodontal disease in the United States". Journal of the American Dental Association 106 (1983): 617-621.

19. American Academy of Periodontology. "Position paper: Tobacco use and the periodontal patient". Journal of Periodontology 70 (1999): 1419-1427.

20. Axelson $P$ and Lindhe J. "The significance of maintenance care in the treatment of periodontal disease". Journal of Clinical Periodontology 8 (1981): 281-294.

21. McGuire M and Scheyer T. "A referral based periodontics practice: yesterday-today-tomorrow". Journal of Periodontology 74 (2003): 1542-1544.

22. Lieberman MB. "Dental ethics". In: Newman MG, Takei HH, Klokkevold PR, Carranza FA, editors. Carranza's clinical periodontology for South Asia: A supplement 11th ed. India: Elsevier (Saunders) (2012): 591-599.

23. Parr RW., et al. "Periodontal maintenance therapy". Berkeley: Calif, Praxis (1974).

24. Parr RW., et al. "Shall I refer?" In: Armitage G. Periodontal maintenance therapy. 2nd ed. Berkeley: Calif, Praxis; 1982.

25. Merin RL. "Supportive periodontal therapy". In: Newman MG, Takei HH, Klokkevold PR, Carranza FA, editors. Carranza's Clinical Periodontology 10th ed. St. Louis, Missouri: Saunders (2006): 1194-1205.

26. Newsome P and Wolfe I. "Value gaps in dental practice". Journal of the American Dental Association 134 (2003): 1500-1504.
27. American Academy of Periodontology. "Position paper: Periodontal maintenance”. Journal of Periodontology 74 (2003): 1395-1401.

28. American Academy of Periodontology. "Position paper: Periodontal disease as a potential risk factor for systemic disease". Journal of Periodontology. 69 (1998): 841-850.

29. American Academy of Periodontology. "Report: The use of conscious sedation by Periodontists". Journal of Periodontology 72 (2001): 1624-1628.

30. American Academy of Periodontology. "Report: Dental implants in periodontal therapy". Journal of Periodontology 71 (2000): 1934-1942.

31. Shaju JP., et al. "Prevalence of periodontitis in the Indian population: A literature review". Journal of Indian Society of Periodontology 15 (2011): 29-34.

\section{Assets from publication with us}

- Prompt Acknowledgement after receiving the article

- Thorough Double blinded peer review

- Rapid Publication

- Issue of Publication Certificate

- High visibility of your Published work

Website: www.actascientific.com/

Submit Article: www.actascientific.com/submission.php Email us: editor@actascientific.com

Contact us: +919182824667 